Supplement of Hydrol. Earth Syst. Sci., 22, 6579-6590, 2018

https://doi.org/10.5194/hess-22-6579-2018-supplement

(c) Author(s) 2018. This work is distributed under

the Creative Commons Attribution 4.0 License.

(c) (1)

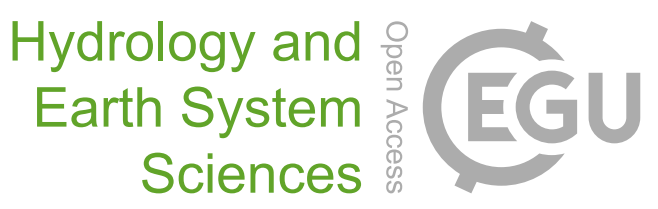

Supplement of

\title{
Dynamic responses of DOC and DIC transport to different flow regimes in a subtropical small mountainous river
}

Yu-Ting Shih et al.

Correspondence to: (riverhuang@ntu.edu.tw)

The copyright of individual parts of the supplement might differ from the CC BY 4.0 License. 


\section{Supplementary Information I. Hydrological modeling for daily and hourly streamflow simulation}

The HBV model (using TUWmodel, ver. 0.1-8., a R package) is a lumped rainfall-runoff model on a catchment scale with a series of three-layer connected storages. Each storage regulates its own runoff, namely, the rapid surface runoff $\left(Q_{R S R}\right)$, slow surface runoff $\left(Q_{S S R}\right)$ and groundwater $\left(Q_{D G}\right)$. The simulated streamflow is the summation of the three runoff types at each time step. This model can be executed with a daily or hourly time step. Briefly speaking, this model considers the processes of evapotranspiration and the generation of the three runoff types. The actual evapotranspiration is proportional to potential evapotranspiration which is a function of temperature, solar radiation and wind speed. The factor of proportionality depends on the current state of the soil moisture content. As precipitation falls, it fills the first storage (upper soil layer). Once the rainfall exceeds the threshold of the upper soil layer, the rapid surface runoff $\left(Q_{R S R}\right)$ is generated. On the other hand, the water in the upper soil layer follows a power law function of current soil moisture content to recharge into the lower soil layer. The recharge rate from the lower soil layer to groundwater is a constant. For each storage, the outflow follows the corresponding streamflow - storage relationship $\left(Q=S^{k}\right)$ to generate its runoff. Finally, a transformation function (function of the parameters, $B_{\max }$ and $C_{\text {route }}$ ) which governs the channel routing is used to reshape the hydrograph at the catchment outlet. Parameter definition and the suggested ranges are listed in Table S1.

Table S1. Definitions and ranges of parameters in the HBV model.

\begin{tabular}{|c|c|c|c|c|}
\hline Parameter & Unit & Description & $\begin{array}{c}\text { Lower } \\
\text { limit }\end{array}$ & $\begin{array}{l}\text { Upper } \\
\text { limit }\end{array}$ \\
\hline LPrat & - & $\begin{array}{l}\text { parameter related to the limit for potential } \\
\text { evaporation }\end{array}$ & 0 & 1 \\
\hline$F C$ & $\mathrm{~mm}$ & field capacity, i.e., max soil moisture storage & 0 & 600 \\
\hline BETA & - & the non-linear parameter for runoff production & 0 & 20 \\
\hline$k_{0}$ & timestep $^{-1}$ & storage coefficient for very fast response & 0 & 2 \\
\hline$k_{1}$ & timestep $^{-1}$ & storage coefficient for fast response & 2 & 30 \\
\hline$k_{2}$ & timestep $^{-1}$ & storage coefficient for slow response & 30 & 250 \\
\hline$L_{s u z}$ & $\mathrm{~mm}$ & $\begin{array}{l}\text { threshold storage state, } \\
\text { i.e., the very fast response start if exceeded }\end{array}$ & 1 & 100 \\
\hline$C_{\text {perc }}$ & $\mathrm{mm}_{\text {day }}{ }^{-1}$ & constant percolation rate & 0 & 8 \\
\hline$B_{\max }$ & timestep $^{-1}$ & maximum base at low flows & 0 & 30 \\
\hline$C_{\text {route }}$ & timestep $^{2} \mathrm{~mm}^{-1}$ & free scaling parameter & 0 & 50 \\
\hline
\end{tabular}




\section{Daily streamflow simulation}

The observed daily streamflow at M3 was used to calibrate the parameters through the performance measure of $N S E$ and $N S E_{\text {log. }}$. The R package DEoptim (Mullen et al., 2011) was applied to optimize the parameter set. The calculation of NSE has been described in the main text and $N S E_{\text {log }}$ shares the same calculation method, but it uses the logarithmic form of streamflow for addressing the variation in low flow conditions. The calibration and validation periods were 2013-2016 and 2005-2012, respectively. The mean annual rainfall during calibration and validation were 2,979 and 3,666 $\mathrm{mm} \mathrm{yr}^{-}$ ${ }^{1}$ and the corresponding streamflows were 2,377 and 3,284 $\mathrm{mm} \mathrm{yr}^{-1}$. The simulations of the calibration were satisfactory with $N S E$ and $N S E_{\log }$ of 0.83 and 0.81 , respectively. Besides, a similar performance was found for the validation period with $N S E$ and $N S E_{\log }$ of 0.79 and 0.81 , respectively. The comparison between the observed and the simulated streamflow is illustrated in Fig. S1 and the calibrated parameter set is shown in Table S2. This calibrated parameter set at M3 was further applied to $\mathrm{T} 1$ and $\mathrm{T} 2$ using their individual climatic inputs to estimate the streamflow of $\mathrm{T} 1$ and $\mathrm{T} 2$.

Table S2. Calibrated parameter sets of the HBV model for daily simulation.

\begin{tabular}{ccc}
\hline Parameter & Unit & Calibrated value \\
\hline LPrat & - & 0.94 \\
$F C$ & $\mathrm{~mm}$ & 285.19 \\
BETA & - & 2.13 \\
$k_{0}$ & day $^{-1}$ & 1.00 \\
$k_{1}$ & day $^{-1}$ & 2.02 \\
$k_{2}$ & day $^{-1}$ & 31.16 \\
$L_{\text {suz }}$ & mm & 42.62 \\
$C_{\text {perc }}$ & mm day $^{-1}$ & 2.24 \\
$B_{\text {max }}$ & day $^{-1}$ & 8.83 \\
$C_{\text {route }}$ & day $^{2} \mathrm{~mm}^{-1}$ & 39.46 \\
\hline
\end{tabular}



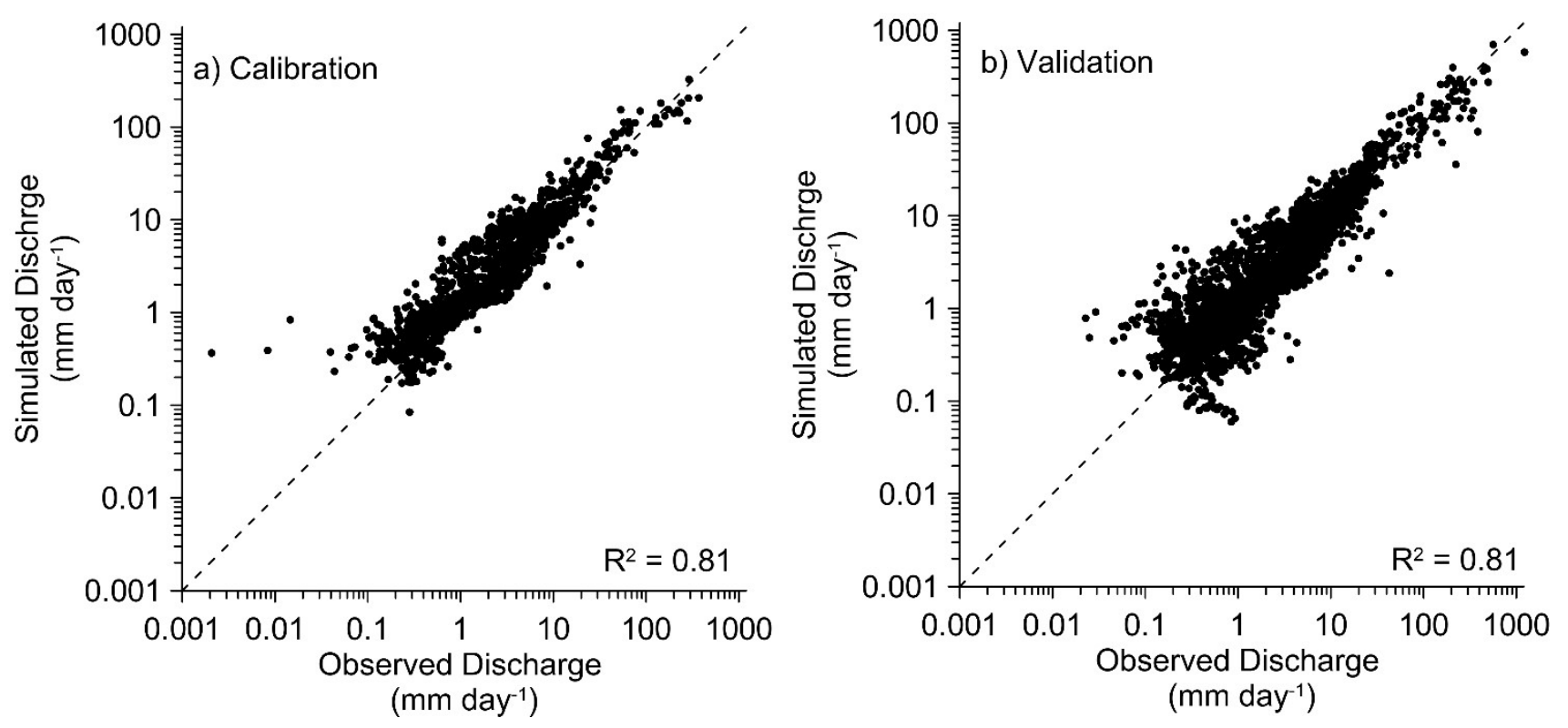

Figure S1. The comparison between observed and simulated daily streamflow during calibration (a) and validation (b) period. Dashed line indicates the 1:1 ratio.

\section{Hourly streamflow simulation}

The event simulation was carried out using daily simulation but with an hourly time step. The calibrated parameter set for the event simulation is shown in Table S3. The parameters of FC, BETA, and $k_{1}$ were quite different from those of the daily simulation indicating the hydrologic behaviors were distinctly different on daily and hourly timescale. The basic information and the simulation performances of the events were listed in Table S4. The average NSE and NSE $E_{l o g}$ for the calibration were 0.86 and 0.79 , respectively. Most events could be satisfactorily modeled, except Typhoon Soulik. The total rainfall of Soulik was not the lowest, whereas the observed streamflow was the lowest probably due to the influence of rainfall heterogeneity. On the other hand, the average of NSE and $N S E_{\log }$ of the validation were 0.79 and 0.81 , respectively, which was at a similar level as for the calibration. The comparison between the observed and the simulated streamflow is illustrated in Fig. $\mathrm{S} 2$.

Table S3. Calibrated parameter sets for hourly streamflow simulation.

\begin{tabular}{llc}
\hline Parameter & Unit & Calibrated value \\
\hline LPrat & - & 0.99 \\
FC & $\mathrm{mm}$ & 102.31 \\
BETA & - & 0.28 \\
$k_{0}$ & $\mathrm{hr}^{-1}$ & 0.30 \\
$k_{1}$ & $\mathrm{hr}^{-1}$ & 29.76 \\
$k_{2}$ & $\mathrm{hr}^{-1}$ & 30.01 \\
$L_{\text {suz }}$ & $\mathrm{mm}$ & 41.38
\end{tabular}




\begin{tabular}{llc}
$C_{\text {perc }}$ & $\mathrm{mm} \mathrm{hr}^{-1}$ & 3.41 \\
$B_{\text {max }}$ & $\mathrm{hr}^{-1}$ & 2.87 \\
$C_{\text {route }}$ & $\mathrm{hr}^{2} \mathrm{~mm}^{-1}$ & 28.79 \\
\hline
\end{tabular}

Table S4. The modeling performances of hourly streamflow simulations

\begin{tabular}{|c|c|c|c|c|c|c|c|}
\hline No. & $\begin{array}{l}\text { Typhoon } \\
\text { (Date) }\end{array}$ & $\begin{array}{l}\text { Duration } \\
\text { (hr) }\end{array}$ & $\begin{array}{l}\text { Rainfall } \\
\text { (mm) }\end{array}$ & $\begin{array}{l}\text { Observed } \\
\text { streamflow } \\
(\mathrm{mm})\end{array}$ & $\begin{array}{l}\text { Simulated } \\
\text { streamflow } \\
(\mathrm{mm})\end{array}$ & NSE & $\mathrm{NSE}_{\log }$ \\
\hline \multicolumn{8}{|c|}{ Calibration } \\
\hline 1 & $\begin{array}{l}\text { Haitang } \\
(2005 / 07 / 17)\end{array}$ & 144 & 1157 & 1133 & 1041 & 0.92 & 0.61 \\
\hline 2 & $\begin{array}{l}\text { Sepat } \\
(2005 / 08 / 18)\end{array}$ & 120 & 708 & 776 & 638 & 0.88 & 0.91 \\
\hline 3 & $\begin{array}{l}\text { Sinlaku } \\
(2008 / 09 / 13)\end{array}$ & 75 & 836 & 758 & 709 & 0.95 & 0.93 \\
\hline 4 & $\begin{array}{l}\text { Morakot } \\
(2009 / 08 / 06)\end{array}$ & 168 & 2205 & 2533 & 2103 & 0.89 & 0.74 \\
\hline 5 & $\begin{array}{l}\text { Saola } \\
(2012 / 07 / 31)\end{array}$ & 84 & 470 & 356 & 362 & 0.97 & 0.94 \\
\hline 6 & $\begin{array}{l}\text { Soulik } \\
(2013 / 07 / 13)\end{array}$ & 48 & 571 & 351 & 497 & 0.55 & 0.52 \\
\hline 7 & $\begin{array}{l}\text { Trami } \\
(2013 / 08 / 21)\end{array}$ & 116 & 1025 & 853 & 810 & 0.90 & 0.77 \\
\hline \multirow[t]{3}{*}{8} & $\begin{array}{l}\text { Kong-Rey } \\
(2013 / 08 / 27)\end{array}$ & 147 & 357 & 478 & 421 & 0.86 & 0.93 \\
\hline & Average & 113 & 916 & 905 & 823 & 0.86 & 0.79 \\
\hline & \multicolumn{7}{|l|}{ Validation } \\
\hline 9 & $\begin{array}{l}\text { Rainstorm } \\
(2012 / 06 / 10)\end{array}$ & 168 & 893 & 1066 & 849 & 0.57 & 0.68 \\
\hline 10 & $\begin{array}{l}\text { Matmo } \\
(2014 / 07 / 22)\end{array}$ & 49 & 344 & 173 & 227 & 0.82 & 0.79 \\
\hline 11 & $\begin{array}{l}\text { Soudelor } \\
(2015 / 08 / 05)\end{array}$ & 51 & 453 & 346 & 303 & 0.89 & 0.93 \\
\hline 12 & $\begin{array}{l}\text { Dujuan } \\
(2015 / 09 / 24)^{*}\end{array}$ & 115 & 592 & 621 & 494 & 0.88 & 0.89 \\
\hline 13 & $\begin{array}{l}\text { Dujuan } \\
(2015 / 09 / 28)\end{array}$ & 53 & 359 & 371 & 266 & 0.81 & 0.77 \\
\hline & Average & 87 & 528 & 515 & 428 & 0.79 & 0.81 \\
\hline
\end{tabular}

*Dujuan had two distinct rainfall peaks and thus it was separated into two events. 

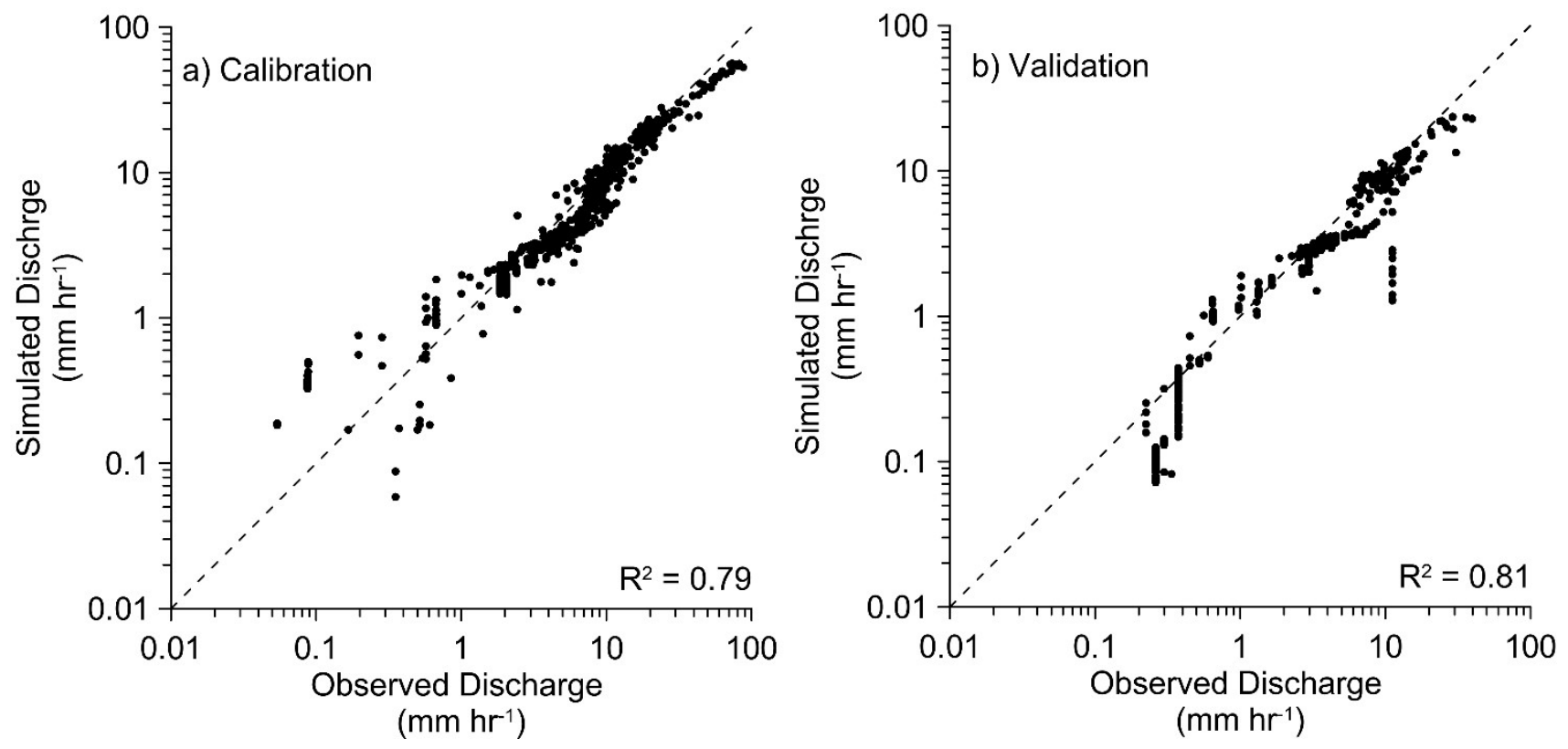

Figure S2. The comparison between observed and simulated streamflow during the calibration (a) and validation (b) events at an hourly scale. Dashed line indicates the 1:1 ratio. 


\section{Supplementary Information II. End-member mixing analysis for identification of C sources}

End-member mixing models are widely used for identifying the mixing proportion and unknown sources of the mixture. In our case, Eq. 4 and Eq. 5 in the main text represent the mass balances of streamflow components and the DOC and DIC concentrations of the three sources. Theoretically, over 6 samples could be used to identify the end-members; however, the estimators should be constrained for avoiding biased inferences. Accordingly, three important issues should be addressed when using end-member mixing: (1) the accuracy of streamflow components $\left(Q_{R S R}, Q_{S S R}\right.$, and $\left.Q_{D G}\right)$; (2) the accuracy of the estimation of end-members (e.g. C sources), and (3) whether the end-member is timevariant or time-invariant. Below, we described the validation of the three issues in our study.

Concerning accuracy of streamflow components, our hourly streamflow was satisfactorily simulated, which could support the estimations of the three streamflow components; however, the three components should be constrained or validated independently. Here, we introduced 4 chemical tracers $\left(\mathrm{EC}, \mathrm{Cl}^{-}, \mathrm{Ca}^{2+}\right.$, and $\mathrm{Mg}^{2+}$ ) in streamwater to evaluate the accuracy of the three streamflow components. The $R^{2}$ values of the tracers for comparing the observed and the estimated of 3 end-members were $0.68,0.36,0.76$ and 0.73 for $\mathrm{EC}, \mathrm{Cl}^{-}, \mathrm{Ca}^{2+}$, and $\mathrm{Mg}^{2+}$, respectively. The $N S E$ values of the tracers were $0.27,0.32,0.76$, and 0.55 , respectively. $\mathrm{Ca}^{2+}$ and $\mathrm{Mg}^{2+}$ which are mainly derived from lithologic formations supported the estimated components. However, $\mathrm{EC}$ and $\mathrm{Cl}^{-}$, which are easily altered by human disturbance and atmospheric deposition did not perform well. Despite the uncertainties in EC and $\mathrm{Cl}^{-}$, the general promising agreement consolidates the reliability of the estimated three components.

Based on the above independent validation of the streamflow components, we identified the DOC and DIC end-members through the mixing analysis with fixed three runoff types. The estimated endmembers of DOC were 108, 206, and $86 \mu \mathrm{M}$ for $Q_{R S R}, Q_{S S R}, Q_{D G}$, respectively. The estimated DIC end-members were 915,1168 , and $2297 \mu \mathrm{M}$ for $Q_{R S R}, Q_{S S R}, Q_{D G}$, respectively. We also collected three water samples from seepage in hillslope as $Q_{S S R}$ and drips in a tunnel as $Q_{D G}$ (Table S5 and Fig. 1 in the main text). The promising agreement indicated that the $\mathrm{C}$ sources identification was reasonable, though the representativeness and spatial heterogeneity of sampling is still a challenge.

Table S5. The DOC and DIC concentrations from seepage and estimated sources

\begin{tabular}{cccccc}
\hline & & \multicolumn{2}{c}{ Observed } & \multicolumn{2}{c}{ Estimated } \\
Samples* & Type & DOC & DIC & DOC & DIC \\
& & $\mu \mathrm{M}$ & $\mu \mathrm{M}$ & $\mu \mathrm{M}$ & $\mu \mathrm{M}$ \\
\hline Hillslope & SSR & 266 & 1033 & 206 & 1168 \\
Toe \#1 & DG & 124 & 2612 & 86 & 2297 \\
Toe \#2 & DG & 58 & 2726 & 86 & 2297 \\
\hline
\end{tabular}

*: The three samples were collected in 2017-01-25, the driest period in our study catchment. 
After constraining the streamflow components and the end-members of DOC and DIC, the timevariant assumption of end-members was also evaluated. Time-variant implies that the end-member should not be assumed constant and dynamic mixing behaviors should be considered. On the other hand, time-invariant end-members usually have slow turnover rates, indicating the end-member can release substance continuously (Mills et al., 2014). In practice, Bertrand-Krajewski et al. (1998) suggested to compare the cumulative substance export against cumulative runoff volume to examine whether the substance export is continuous. The continuous export implies a relatively slow turnover rate of the source. The cumulative DOC and DIC export against cumulative runoff volume are shown in Fig. S3. In this figure, both DOC and DIC export smoothly follow the 1:1 ratio of the cumulative export and runoff. The DOC release is a little higher than the runoff indicating that the DOC is likely enhanced or flushed out. Nevertheless, this plot suggests that the DOC and DIC are continuously being released during a typhoon event and a slow turnover rate could be inferred. Although we do not know whether the assumption of time-invariant end-member can hold for all unsampled cases in reality (a more robust methodology needs to be proposed), the continuous releasing and slow turnover rate likely support the time-invariant assumption in our two cases.
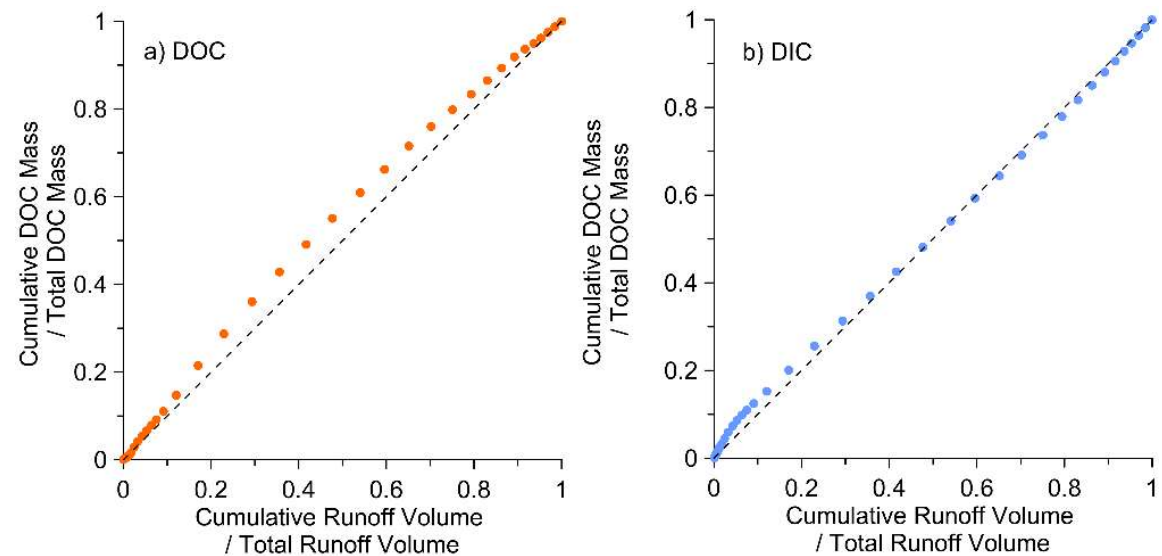

Figure S3. The cumulative export against cumulative runoff volume for (a) DOC and (b) DIC during typhoon Matmo. The dashed line shows the 1:1 ratio of cumulative export and runoff.

\section{Supplementary Reference}

Bertrand-Krajewski, J.-L., Chebbo, G., and Saget, A.: Distribution of pollutant mass vs volume in stormwater discharges and the first flush phenomenon, Water Res., 32, 2341-2356, https://doi.org/10.1016/S0043-1354 (97)00420-X, 1998.

Mills, R. T. E., Tipping, E., Bryant, C. L., and Emmett, B. A.: Long-term organic carbon turnover rates in natural and semi-natural topsoils, Biogeochemistry, 118, 257-272, 10.1007/s10533-0139928-z, 2014.

Mullen, K. M., Ardia, D., Gil, D. L., Windover, D., and Cline, J.: DEoptim: An R Package for Global Optimization by Differential Evolution, Journal of Statistical Software, 40, 1-26, 2011. 